\title{
Correction to: Intramedullary screw fixation for simple displaced olecranon fractures
}

\author{
Willem Maarten P. F. Bosman ${ }^{1,2}\left(\right.$ C $\cdot$ Benjamin L. Emmink $k^{1,3} \cdot$ Abhiram R. Bhashyam $^{3,4,5} \cdot$ R. Marijn Houwert ${ }^{3}$. \\ Jort Keizer ${ }^{1}$
}

Published online: 25 November 2019

○) Springer-Verlag GmbH Germany, part of Springer Nature 2019

\section{Correction to: \\ European Journal of Trauma and Emergency Surgery https://doi.org/10.1007/s00068-019-01114-4}

The original version of this article unfortunately contained some mistakes. The spelling of the Willem Maarten P. F. Bosmans' name was incorrect. The correct information is given above.

The original article can be found online at https://doi.org/10.1007/ s00068-019-01114-4.

Willem Maarten P. F. Bosman

w.m.bosman@asz.nl

1 Department of Surgery, St Antonius Hospital, Utrecht, The Netherlands

2 Department of Surgery, Albert Schweitzer Hospital, Dordrecht, The Netherlands

3 Department of Trauma Surgery, University Medical Center, Utrecht, The Netherlands

4 Harvard Combined Orthopaedic Residency Program, Harvard University, Boston, MA, USA

5 Harvard Medical School, Boston, MA, USA 